\title{
Recurrence risk after preoperative biopsy in patients with resected early-stage non-small-cell lung cancer: a retrospective study
}

This article was published in the following Dove Press journal: Cancer Management and Research

\author{
Chengping $\mathrm{Hu}^{\prime}$ \\ Juan Jiang' \\ Yuanyuan $\mathrm{Li}^{\prime}$ \\ Chunfang Zhang ${ }^{2}$ \\ Weixing Zhang ${ }^{2}$ \\ Haihe Jiang ${ }^{2}$ \\ Yang $\mathrm{Gao}^{2}$ \\ Wei Zhuang ${ }^{2}$ \\ Kaibo Lei $^{2}$ \\ Yong Tang ${ }^{2}$ \\ Rongjun Wan' \\ 'Department of Respiratory and \\ Critical Care Medicine, National Key \\ Clinical Specialty, Xiangya Hospital, \\ Central South University, Changsha, \\ China; ${ }^{2}$ Department of Thoracic \\ Surgery, Xiangya Hospital, Central \\ South University, Changsha, China
}

Correspondence: Yuanyuan Li

Department of Respiratory and Critical

Care Medicine, Xiangya Hospital, Central

South University, 87 Xiangya Road, Kaifu

District, Changsha 410008, China

Tel +86 I397580 6790

Email leeround@csu.edu.cn
Background: Tumor cell dissemination after needle biopsy has been reported in a variety of malignancies, including non-small-cell lung cancer (NSCLC). However, there is little clinical evidence in regard to whether preoperative biopsy increases the risk of recurrence in completely resected NSCLC.

Patients and methods: A total of 322 patients diagnosed as pathological stage I NSCLC using intraoperative biopsy (IOB) (control group), preoperative percutaneous needle biopsy (PNB) or bronchoscopic biopsy were included in this study. Baseline characteristics were collected and compared. The disease-free survival (DFS) of patients was analyzed using Kaplan-Meier method. Subgroup analysis and Cox regression were performed to evaluate the effect of preoperative biopsy on recurrence risk with adjustment for potential confounders.

Results: Among these patients, 202 (63\%) underwent IOB, 66 (20\%) underwent PNB, and 54 (17\%) underwent bronchoscopic biopsy. DFS of patients who had preoperative PNB or bronchoscopic biopsy was similar to those who had IOB $(P=0.514$ and 0.869$)$. Neither preoperative PNB nor transbronchial biopsy significantly affected recurrence incidence across all the relevant subgroups. Furthermore, multivariate analysis showed that preoperative biopsy was not associated with increased recurrence risk in NSCLC patients with adjustment for confounders, while squamous cell carcinoma and adjuvant chemotherapy were associated with prolonged DFS.

Conclusion: Neither preoperative PNB nor bronchoscopic biopsy increased the recurrence risk in patients with resected stage I NSCLC, indicating that these procedures could be safely used for diagnosis of early-stage NSCLC.

Keywords: non-small-cell lung cancer, biopsy, recurrence, percutaneous needle biopsy, bronchoscopy, surgery

\section{Introduction}

Lung cancer is the leading cause of cancer death among both men and women. ${ }^{1}$ Non-small-cell lung cancer (NSCLC) accounts for $\sim 85 \%$ of lung cancer. ${ }^{2}$ Currently, preoperative biopsy, including percutaneous needle biopsy (PNB) and bronchoscopic biopsy, has been widely used for pathological diagnosis of pulmonary nodules suspected as lung cancer. These diagnostic methods are highly accurate, minimally invasive, and can potentially benefit patients by providing a definite diagnosis and more flexible treatment options before surgery. ${ }^{3}$

While preoperative PNB and bronchoscopic biopsy are believed to improve the accuracy and efficiency in NSCLC diagnosis, there has been a concern that these procedures may cause tumor cell dissemination, thus increasing recurrence incidence after surgery. Tumor cells, on one hand, may contaminate the biopsy needles and seed along 
the biopsy route. ${ }^{4-8}$ On the other hand, since malignancies are enriched in blood supply, there is a possibility that tumor cells displaced during biopsy, such as PNB and bronchoscopic biopsy, may enter the bloodstream and lead to metastasis in certain organs. ${ }^{9-11}$ Previously, several retrospective studies have explored the potential influence of preoperative PNB on pleural recurrence risk in early-stage NSCLC. But the clinical outcome assessed in these studies was only local recurrence limited to pleura, and their conclusions were contradictory. ${ }^{12-16}$ Besides, patients who had bronchoscopic biopsy were either excluded or used as control subjects for analysis together with those who had intraoperative biopsy (IOB). Therefore, whether preoperative biopsy could increase the risk of total recurrence by triggering hematogenous dissemination in NSCLC patients still remains unknown.

Herein, we retrospectively investigated the potential influence of preoperative PNB and bronchoscopic biopsy on recurrence risk in stage I NSCLC patients who underwent curative surgeries at our hospital.

\section{Patients and methods}

\section{Patients}

A review of the medical records was made of all 868 NSCLC patients who underwent complete resection between January 2010 and September 2014 at Xiangya Hospital, Central South University (Changsha, China). The inclusion criteria for patient were listed as follows: solitary pulmonary lesions on radiological images presenting as suspected lung cancer; completely resected NSCLC; diagnosis of NSCLC confirmed by pathological examination of surgical tissue specimens; and pathological stage I NSCLC (the seventh edition of tumor-node-metastasis staging system). Patients with comorbidity of other malignancies or who were lost to follow-up were excluded. A total of 466 patients confirmed as stage II NSCLC, 71 patients lost to follow-up, 3 patients with comorbidity of other malignancies, and 6 patients with incomplete medical records were excluded. Finally, 322 patients were included in this study. The median follow-up period for the entire cohort was 78 months. This study was approved by the Institutional Review Board and Ethics Committee of Central South University. Written informed consent was waived as this was a retrospective study.

\section{Diagnostic methods}

PNB, bronchoscopic biopsy, and IOB were performed for pathologic diagnosis of NSCLC in a single-center (Xiangya Hospital) setting using standard methods.
For PNB, computed tomography (CT) scans were performed at $110 \mathrm{kV}, 25 \mathrm{~mA}$ using a $4 \times 1.25 \mathrm{~mm}$ collimation (Philips, Amsterdam, The Netherlands). After an initial CT examination for biopsy planning, needle access was chosen individually according to the tumor localization. The semiautomatic biopsy system 18G (TSK Laboratory, Tochigi-Ken, Japan) was used to take tumor samples.

Bronchoscopic biopsy was performed under local anesthesia in standard fashion as previously described. ${ }^{17}$ BF-260 video bronchoscope (Olympus, Tokyo, Japan) was used and tumor samples were taken with regular disposable biopsy forceps. In patients whose lesions could not be directly seen under bronchoscope, biopsy was performed under the guidance of endobronchial ultrasonography.

IOB was performed by the Department of Thoracic Surgery, Xiangya Hospital. ${ }^{18}$ Briefly, the pulmonary lesion was completely resected, with a $2 \mathrm{~cm}$ surgical margin or a margin equivalent to the maximal diameter of the lesion. Tissue samples were subsequently obtained from the resected pulmonary lesions, immediately put into $10 \%$ neutral buffered formalin, and sent to the Department of Pathology for rapid frozen section analysis. If the pulmonary lesion was confirmed as malignancy, lobectomy or pneumonectomy and systemic lymphadenectomy were further performed to achieve a curative resection. Tumor tissue samples were obtained from the resected tumors and again sent to the Department of Pathology for pathological examination, the result of which was used as the golden standard of final diagnosis for patients.

Bronchoscopic evaluation of all the patients was made by pulmonologists at the hospital.

\section{Assessment of recurrence}

We reviewed the medical records of all patients to analyze disease-free survival (DFS). DFS was defined as the period of time that patients were left with no detectable disease after complete surgical resection of primary tumors in lung. Recurrence events were determined if any of the following happened after curative surgery: malignant pleural or pericardial effusion; pleural malignant nodules in thoracic imaging; intrapulmonary recurrences or metastases; and extrathoracic metastases. Local recurrences were defined as any recurrences within the ipsilateral thorax.

\section{Statistical analysis}

The normal distribution of tumor sizes in NSCLC patients was confirmed by one-sample Kolmogorov-Smirnov test, and subsequently the unpaired $t$-test was used to compare 
the tumor sizes of patients who underwent PNB, bronchoscopic biopsy, or IOB. Otherwise, the differences in baseline characteristics were compared using the chi-square test. The Kaplan-Meier method was used to estimate survival rates. Using the log-rank test, we compared DFS of patients in different groups. The association of PNB or bronchoscopic biopsy with recurrence incidence was evaluated by conducting subgroup analysis and Cox proportional hazard regression model. All statistical analyses were carried out using the SPSS Statistics version 24.0 (IBM Corp, Armonk, NY, USA). A $P$-value $<0.05$ was considered to be statistically significant.

\section{Results}

\section{Baseline characteristics of patients}

As shown in Table 1, a total of 322 NSCLC patients were included in this study. Among them, 66 underwent preoperative PNB, 54 underwent preoperative bronchoscopic biopsy, and 202 underwent IOB as part of the diagnostic workup. Compared with IOB, PNB was more frequently performed in patients with larger-sized tumor $(2.52 \pm 0.07$ vs $2.33 \pm 0.06$ $\mathrm{cm}, P=0.015)$ and squamous cell carcinoma (SCC) (30\% vs $17 \%, P=0.031)$. All other baseline clinicopathologic characteristics were not significantly different between PNB and IOB groups. In contrast, bronchoscopic biopsy was far more frequently used in male $(96 \%$ vs $57 \%, P<0.001)$ patients of SCC ( $86 \%$ vs $17 \%, P<0.001)$, and those with smoking history $(83 \%$ vs $44 \%, P<0.001)$ and later T stage (59\% vs $23 \%$, $P<0.001)$ in comparison with IOB. Additionally, thoracotomy $(87 \%$ vs $51 \%, P<0.001)$ was more frequently applied in patients of bronchoscopic biopsy group.

\section{Unadjusted survival analysis}

Recurrence pattern of NSCLC patients included in this study is shown in Table 2. Brain, bone, and ipsilateral thorax were the most frequent recurrence locations. DFS curves were similar among patients who underwent PNB, bronchoscopic biopsy, or IOB, as determined by Kaplan-Meier analysis (Figure 1). No significant difference in overall DFS was observed.

Table I Baseline characteristics of patients with resected early-stage NSCLC

\begin{tabular}{|c|c|c|c|c|}
\hline Characteristics & PNB, $n=66$ (\%) & $\begin{array}{l}\text { Bronchoscopic } \\
\text { biopsy, } n=54(\%)\end{array}$ & IOB, $n=202$ (\%) & $P$-value \\
\hline \multicolumn{5}{|l|}{ Gender } \\
\hline Male & $34(52)$ & $52(96)$ & $115(57)$ & 0.477 \\
\hline Female & $32(48)$ & $2(4)$ & $87(43)$ & $<0.001$ \\
\hline \multicolumn{5}{|l|}{ Age (years) } \\
\hline$<50$ & $16(24)$ & $6(11)$ & $43(21)$ & 0.083 \\
\hline $50-60$ & $17(26)$ & $25(46)$ & $86(43)$ & 0.233 \\
\hline$>60$ & $33(50)$ & $23(43)$ & $73(36)$ & \\
\hline \multicolumn{5}{|l|}{ Smoking history } \\
\hline Yes & $28(42)$ & $45(83)$ & $89(44)$ & 0.887 \\
\hline No & $38(58)$ & $9(17)$ & $113(56)$ & $<0.001$ \\
\hline \multicolumn{5}{|l|}{ T stage } \\
\hline I & $41(62)$ & $23(4 I)$ & $156(77)$ & 0.024 \\
\hline II & $25(38)$ & $31(59)$ & $46(23)$ & $<0.001$ \\
\hline Tumor size $(\mathrm{cm})$ & $2.52 \pm 0.07$ & $2.54 \pm 0.09$ & $2.33 \pm 0.06$ & $0.015,0.230$ \\
\hline \multicolumn{5}{|l|}{ Pathology } \\
\hline$A D$ & $46(70)$ & $4(7)$ & $160(79)$ & 0.031 \\
\hline SCC & $20(30)$ & $46(86)$ & $35(17)$ & $<0.001$ \\
\hline Others & $0(0)$ & $4(7)$ & $7(4)$ & \\
\hline \multicolumn{5}{|l|}{ Differentiation } \\
\hline Good & $12(18)$ & $4(7)$ & $16(8)$ & 0.102 \\
\hline Moderate & $29(44)$ & $34(63)$ & $83(4 I)$ & $<0.001$ \\
\hline Poor & $19(29)$ & $14(26)$ & $52(26)$ & \\
\hline NR & $6(9)$ & $2(4)$ & $51(25)$ & \\
\hline \multicolumn{5}{|l|}{ Surgery types } \\
\hline Thoracotomy & $34(52)$ & $47(87)$ & $105(5 \mathrm{I})$ & 0.930 \\
\hline VATS & $32(48)$ & $7(13)$ & $97(49)$ & $<0.001$ \\
\hline \multicolumn{5}{|l|}{ Chemotherapy } \\
\hline Yes & $27(4 I)$ & $27(50)$ & $71(35)$ & 0.462 \\
\hline No & $39(59)$ & $27(50)$ & $13 \mid(65)$ & 0.068 \\
\hline
\end{tabular}

Note: The $2 P$-values refer to PNB vs IOB and bronchoscopic biopsy vs IOB, respectively.

Abbreviations: AD, adenocarcinoma; IOB, intraoperative biopsy; PNB, percutaneous needle biopsy; NR, not recorded; NSCLC, non-small-cell lung cancer; SCC, squamous cell carcinoma; VATS, video-assisted thoracoscopic surgery. 
Table 2 Recurrence patterns of patients with resected earlystage NSCLC

\begin{tabular}{llll}
\hline Patient number & PNB & $\begin{array}{l}\text { Bronchoscopic } \\
\text { biopsy }\end{array}$ & IOB \\
\hline Recurrence & $21(32 \%)$ & $18(33 \%)$ & $60(30 \%)$ \\
Distant recurrence & 6 & 6 & 17 \\
$\quad$ Brain & 5 & 4 & 15 \\
Bone & 2 & 1 & 5 \\
Abdomen & 2 & 2 & 4 \\
$\quad$ Contralateral lung & 4 & 4 & 14 \\
Local recurrence & 2 & 1 & 5 \\
Combined recurrence & 2 & \\
\hline
\end{tabular}

Abbreviations: IOB, intraoperative biopsy; NSCLC, non-small-cell lung cancer; PNB, percutaneous needle biopsy.

\section{Subgroup analysis}

Since some baseline characteristics of patients who underwent PNB or bronchoscopic biopsy were significantly different from that of the patients in IOB group, we further performed subgroup analysis to control the influences of confounders. Neither PNB nor bronchoscopic biopsy affected the risk of recurrence across relevant subgroups (Tables 3 and 4). Several subgroups (female, adenocarcinoma and video-assisted thoracoscopic surgery subgroups, etc.) were not included in the comparison between bronchoscopic biopsy and IOB because sample number was too small.

\section{Cox regression analysis}

Univariate analysis was performed to determine the potential prognostic factors of DFS in patients with resected stage I NSCLC. It revealed that tumor size, histologic subtypes, surgery types, and adjuvant chemotherapy were associated with DFS (Table 5). Subsequently, multivariate analysis demonstrated that SCC (hazard ratio [HR], 0.65; 95\% CI: $0.41-0.96 ; P=0.036)$ and adjuvant chemotherapy (HR, 0.56 ; 95\% CI: $0.44-0.73 ; P<0.001)$ were independent prognostic factors of DFS (Table 6). Preoperative PNB (HR, 1.08; 95\% CI: $0.55-2.15 ; P=0.821$ ) and bronchoscopic biopsy (HR, $0.78 ; 95 \%$ CI: $0.48-1.26 ; P=0.302$ ) were not associated with DFS after adjusting for tumor size, histologic subtypes, surgery types, and adjuvant chemotherapy (Table 6).

\section{Discussion}

PNB and bronchoscopic biopsy are commonly used diagnostic methods for pulmonary lesions when there is a suspicion of lung cancer. However, there has been a concern that invasive biopsy procedures may cause tumor cell dissemination, thus increasing the recurrence risk after radical resection. In the present study, we found that preoperative PNB and bronchoscopic biopsy did not increase recurrence incidence in early-stage NSCLC patients after curative surgery.

Malignancies are usually well vascularized. When a needle or forceps for biopsy is inserted into the tumor, displacement of a small amount of tumor cells is theoretically unavoidable. These cells may enter the bloodstream and colonize in certain sites if they are not eliminated by human immune system. ${ }^{9}$ In this case, preoperative biopsy might cause recurrence in NSCLC patients, but this possibility has been barely investigated yet. In this study, we retrospectively analyzed the recurrence outcomes of NSCLC patients who underwent preoperative PNB, bronchoscopic biopsy, or IOB at our hospital. Our data revealed that preoperative PNB or bronchoscopic biopsy did not significantly affect DFS in NSCLC patients after radical resection. Since bronchoscopic biopsy is much more applicable to the diagnosis of central type lung cancer, it was not surprising that most cases in the bronchoscopic biopsy group were male smoker patients with SCC, and the therapeutic methods used in these patients were also different from other groups. Therefore, subgroup analysis and Cox regression were performed to control the imbalance of unmatched baseline characteristics. Compared with IOB, no significant difference in recurrence risk was observed in patients who had preoperative PNB or bronchoscopic biopsy, suggesting that these procedures are safe diagnostic methods without increasing recurrence incidence. In addition, based on our data, histologic subtype and adjuvant chemotherapy were independent prognostic factors of DFS in NSCLC patients, which was consistent with previous studies. ${ }^{19,20}$ It is worth noting that, in the present study, 38.8\% (125/322) of NSCLC patients underwent adjuvant chemotherapy, and all of them were evaluated as pathological stage IB NSCLC. Actually, whether adjuvant chemotherapy should be applied in stage IB NSCLC has remained controversial so far. According to National Comprehensive Cancer Network guidelines, adjuvant chemotherapy could be appropriate for stage IB NSCLC patients with highrisk factors, such as poorly differentiated tumors, vascular invasion, tumors $>4 \mathrm{~cm}$, and visceral pleural involvement. Recently, increasing amount of clinical studies has revealed the benefits of adjuvant chemotherapy for stage IB NSCLC patients. ${ }^{21,22}$ These studies and our data consistently supported the beneficial effect of adjuvant chemotherapy in high-risk stage IB NSCLC patients.

Whether biopsy can cause cancer cells to spread is controversial. It has been reported that needle biopsy may shed cancer cells into peripheral blood, as indicated by 

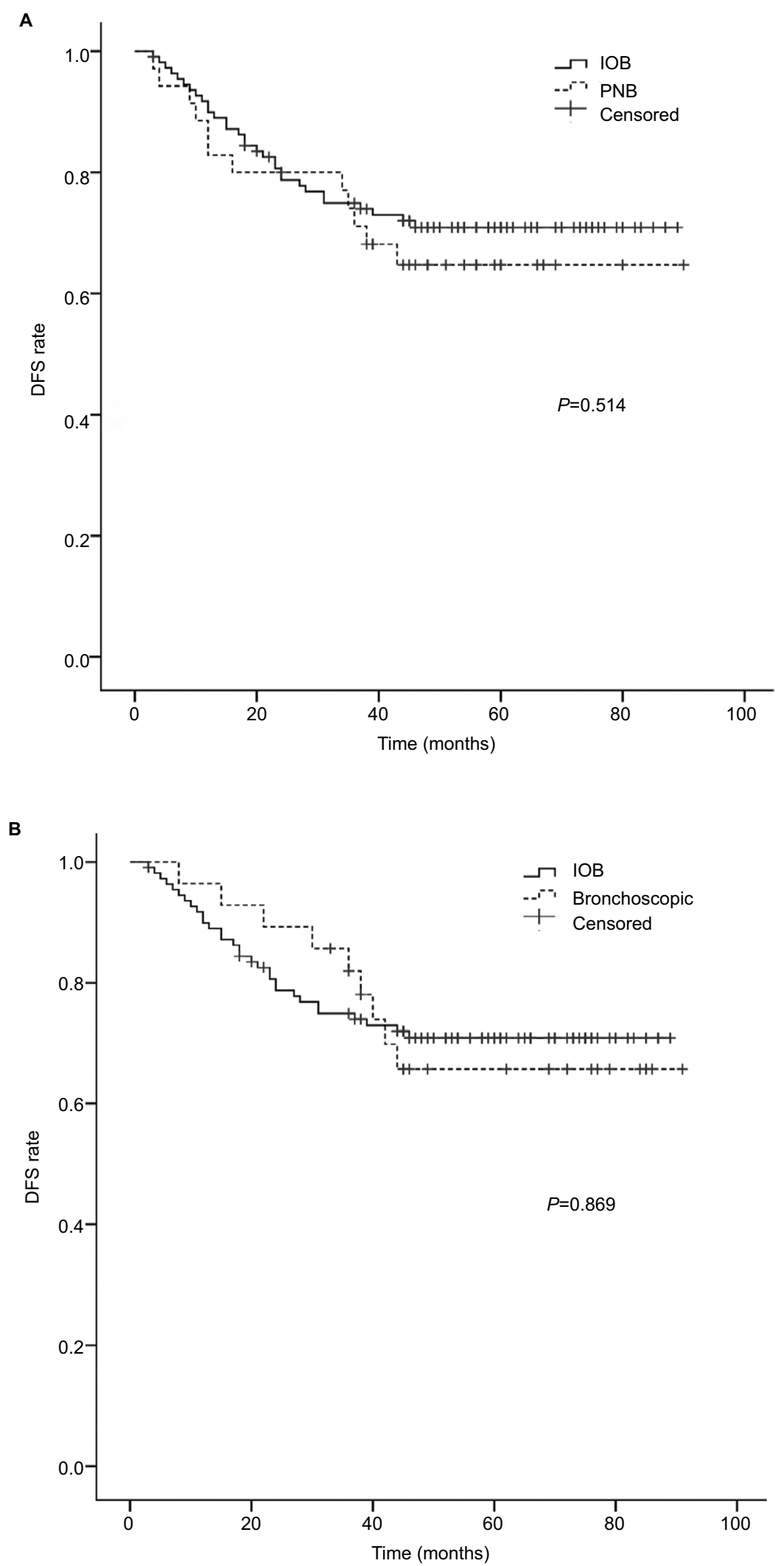

Figure I Preoperative percutaneous needle biopsy and bronchoscopic biopsy did not increase recurrence incidence in NSCLC patients.

Notes: (A) DFS curves for patients who had percutaneous needle biopsy or intraoperative biopsy. (B) DFS curves for patients who had bronchoscopic biopsy or intraoperative biopsy.

Abbreviations: DFS, disease-free survival; IOB, intraoperative biopsy; NSCLC, non-small-cell lung cancer; PNB, percutaneous needle biopsy. 
Table 3 Subgroup analysis of recurrence risk in NSCLC patients who underwent percutaneous needle biopsy

\begin{tabular}{|c|c|c|c|}
\hline \multirow[t]{2}{*}{ Characteristics } & \multicolumn{3}{|c|}{ Recurrence } \\
\hline & HR & $95 \% \mathrm{Cl}$ & $P$-value \\
\hline \multicolumn{4}{|l|}{ Gender } \\
\hline Male & 1.73 & $0.80-3.52$ & 0.143 \\
\hline Female & 0.68 & $0.23-2.14$ & 0.551 \\
\hline \multicolumn{4}{|l|}{ Age (years) } \\
\hline$<50$ & 0.46 & $0.13-3.46$ & 0.482 \\
\hline $50-60$ & 1.53 & $0.46-5.06$ & 0.515 \\
\hline$>60$ & 1.41 & $0.63-3.45$ & 0.498 \\
\hline \multicolumn{4}{|l|}{ Smoking history } \\
\hline Yes & 2.09 & $0.91-4.85$ & 0.084 \\
\hline No & 0.58 & $0.18-1.89$ & 0.305 \\
\hline \multicolumn{4}{|l|}{$T$ stage } \\
\hline I & 0.95 & $0.46-1.97$ & 0.912 \\
\hline II & 1.62 & $0.49-5.30$ & 0.428 \\
\hline \multicolumn{4}{|l|}{ Pathology } \\
\hline$A D$ & 0.86 & $0.34-2.23$ & 0.785 \\
\hline SCC & 1.32 & $0.52-3.48$ & 0.490 \\
\hline \multicolumn{4}{|l|}{ Differentiation } \\
\hline Good & 1.18 & $0.45-3.10$ & 0.742 \\
\hline Moderate & 1.52 & $0.53-4.39$ & 0.440 \\
\hline Poor & 1.67 & $0.7 I-3.58$ & 0.633 \\
\hline \multicolumn{4}{|l|}{ Surgery types } \\
\hline Thoracotomy & 1.03 & $0.44-2.42$ & 0.949 \\
\hline VATS & 1.65 & $0.57-3.59$ & 0.350 \\
\hline \multicolumn{4}{|l|}{ Chemotherapy } \\
\hline Yes & 1.09 & $0.55-2.38$ & 0.765 \\
\hline No & 1.27 & $0.65-2.69$ & 0.758 \\
\hline
\end{tabular}

Abbreviations: $A D$, adenocarcinoma; HR, hazard ratio; NSCLC, non-small-cell lung cancer; SCC, squamous cell carcinoma; VATS, video-assisted thoracoscopic surgery.

significantly increased mRNA levels of tumor markers after biopsy. ${ }^{10,11}$ However, entry of a small number of tumor cells into blood does not necessarily lead to recurrence or metastases. Instead, in most cases, these cells die soon due to anoikis or are eliminated by immune systems, and successful metastatic colonization is a more inefficient business even though several cells survive in the bloodstream. ${ }^{23}$ Indeed, there is increasing amount of clinical evidence strongly supporting that preoperative biopsy does not spread cancer or affect survival outcomes in patients with malignancies. ${ }^{24-26}$

In terms of lung cancer, several cases of tumor cell implantation ${ }^{4-8}$ and increased incidence of pleural recurrence after needle biopsy have been reported in NSCLC patients. ${ }^{12,13,15}$ However, Sano et al reported that preoperative percutaneous CT-guided needle biopsy did not lead to pleural dissemination, as determined by intraoperative pleural lavage cytology in patients with lung cancer. ${ }^{27}$ Recent studies also demonstrated that PNB was not associated with increased pleural recurrence or impaired survival outcomes in NSCLC
Table 4 Subgroup analysis of recurrence risk in NSCLC patients who underwent bronchoscopic biopsy

\begin{tabular}{|c|c|c|c|}
\hline \multirow[t]{2}{*}{ Characteristics } & \multicolumn{3}{|c|}{ Recurrence } \\
\hline & HR & $95 \% \mathrm{Cl}$ & $P$-value \\
\hline \multicolumn{4}{|l|}{ Gender } \\
\hline Male & 1.05 & $0.65-1.78$ & 0.930 \\
\hline \multicolumn{4}{|l|}{ Age (years) } \\
\hline$<50$ & 1.53 & $0.80-3.14$ & 0.312 \\
\hline $50-60$ & 1.14 & $0.68-1.92$ & 0.624 \\
\hline$>60$ & 0.86 & $0.35-1.79$ & 0.469 \\
\hline \multicolumn{4}{|l|}{ Smoking history } \\
\hline Yes & 1.09 & $0.63-1.77$ & 0.924 \\
\hline No & 1.23 & $0.62-2.45$ & 0.499 \\
\hline \multicolumn{4}{|l|}{ T stage } \\
\hline 1 & 0.85 & $0.46-1.52$ & 0.583 \\
\hline II & 1.26 & $0.75-2.18$ & 0.611 \\
\hline \multicolumn{4}{|l|}{ Pathology } \\
\hline SCC & 0.65 & $0.38-1.07$ & 0.085 \\
\hline \multicolumn{4}{|l|}{ Differentiation } \\
\hline Moderate & 1.05 & $0.63-1.74$ & 0.786 \\
\hline Poor & 0.98 & $0.55-1.78$ & 0.903 \\
\hline \multicolumn{4}{|l|}{ Surgery types } \\
\hline Thoracotomy & 0.94 & $0.64-1.39$ & 0.758 \\
\hline \multicolumn{4}{|l|}{ Chemotherapy } \\
\hline Yes & 1.02 & $0.48-2.05$ & 0.959 \\
\hline No & 0.92 & $0.60-1.40$ & 0.684 \\
\hline
\end{tabular}

Abbreviations: HR, hazard ratio; NSCLC, non-small-cell lung cancer; SCC, squamous cell carcinoma.

Table 5 Univariate analysis of prognostic factors for DFS in NSCLC patients after radical resection

\begin{tabular}{llll}
\hline Characteristics & DFS & & \\
\cline { 2 - 4 } & HR & 95\% Cl & P-value \\
\hline Gender (female vs male) & 0.69 & $0.38-1.26$ & 0.225 \\
Age (years) & 0.97 & $0.75-1.26$ & 0.821 \\
Smoking history (yes vs no) & 0.82 & $0.55-1.23$ & 0.336 \\
T stage (I vs II) & 1.08 & $0.71-1.65$ & 0.711 \\
Tumor size (cm) & 1.52 & $1.10-2.15$ & 0.037 \\
Pathology (SCC vs AD) & 0.63 & $0.45-0.89$ & 0.008 \\
Differentiation & & & \\
$\quad$ Good vs poor & 1.13 & $0.52-2.75$ & 0.542 \\
Surgery types & & & \\
$\quad$ Thoracotomy vs VATS & 0.67 & $0.33-0.82$ & 0.009 \\
Chemotherapy (yes vs no) & 0.41 & $0.32-0.59$ & $<0.001$ \\
Biopsy methods (vs IOB) & & & \\
$\quad$ PNB & 1.18 & $0.75-1.93$ & 0.302 \\
$\quad$ Bronchoscopic biopsy & 1.03 & $0.78-1.36$ & 0.833 \\
\hline
\end{tabular}

Abbreviations: $A D$, adenocarcinoma; $D F S$, disease-free survival; $H R$, hazard ratio; IOB, intraoperative biopsy; NSCLC, non-small-cell lung cancer; PNB, percutaneous needle biopsy; SCC, squamous cell carcinoma; VATS, video-assisted thoracoscopic surgery.

patients. ${ }^{14,16,28}$ Importantly, a recent meta-analysis, including these related observational studies revealed that PNB did not increase the risk of pleural recurrence compared with non-percutaneous transthoracic needle biopsy strategies in 
Table 6 Multivariate analysis of prognostic factors for DFS in NSCLC patients after radical resection

\begin{tabular}{llll}
\hline Characteristics & \multicolumn{2}{l}{ DFS } & \\
\cline { 2 - 4 } & HR & $\mathbf{9 5 \%} \mathbf{~ C l}$ & P-value \\
\hline Tumor size (cm) & 1.59 & $0.95-2.66$ & 0.081 \\
Pathology (SCC vs AD) & 0.65 & $0.41-0.96$ & 0.036 \\
Thoracotomy vs VATS & 0.63 & $0.33-1.20$ & 0.161 \\
Chemotherapy (yes vs no) & 0.56 & $0.44-0.73$ & $<0.001$ \\
Biopsy methods (vs IOB) & & & \\
$\quad$ PNB & 1.08 & $0.55-2.15$ & 0.821 \\
$\quad$ Bronchoscopic biopsy & 0.78 & $0.48-1.26$ & 0.302 \\
\hline
\end{tabular}

Abbreviations: $A D$, adenocarcinoma; DFS, disease-free survival; $H R$, hazard ratio; IOB, intraoperative biopsy; PNB, percutaneous needle biopsy; SCC, squamous cell carcinoma; VATS, video-assisted thoracoscopic surgery.

early-stage lung cancer patients..$^{29}$ The difference between the present study and the previous ones is that, since the application of coaxial biopsy needles has greatly reduced the incidence of needle track implantation, we are now focusing on the possibility of hematogenous dissemination after biopsy. Therefore, total recurrence, instead of pleural recurrence, was used as an endpoint event of interest in the present study. Additionally, we also investigated the potential influence of bronchoscopic biopsy on recurrence, because bronchoscopic biopsy is also invasive and could theoretically cause tumor cell displacement like PNB. Collectively, previous studies and our data support that preoperative PNB and bronchoscopic biopsy are safe diagnostic methods without increasing recurrence in NSCLC. But this knowledge should not interfere with surgical techniques that may benefit the patient by limiting procedural morbidity.

Several limitations should be noted in the present study. First, patient selection bias is unavoidable because this is a single-center retrospective study. The relatively small number of patients, which is partially caused by the strict inclusion criteria and long-term follow-up, also reduces the validity when interpreting the results. In addition, the subjects in this study were stage I NSCLC patients presenting as solitary pulmonary lesions in radiological images. Thus, we could not conclude whether these findings are applicable to other NSCLC populations. More studies with larger patient numbers are required to solve this issue.

\section{Conclusion}

The present study showed that preoperative biopsy, including PNB or bronchoscopic biopsy, was not associated with increased risk of recurrence and did not affect DFS in resected stage I NSCLC patients. Therefore, the use of these diagnostic procedures should be considered in the management of patients with pulmonary nodules suspected as early-stage NSCLC.

\section{Acknowledgments}

This work was supported in part by grants from the National Natural Science Foundation of China (81600025) and the National Key Research and Development Program of China (SQ2016YFSF110276).

\section{Disclosure}

The authors report no conflicts of interest in this work.

\section{References}

1. Siegel RL, Miller KD, Jemal A. Cancer statistics, 2016. CA Cancer J Clin. 2016;66(1):7-30.

2. Li JJ, Li R, Wang W, et al. IDH2 is a novel diagnostic and prognostic serum biomarker for non-small-cell lung cancer. Mol Oncol. 2018;12(5):602-610.

3. Xiao D, Lu C, Zhu W, et al. Comparison of small biopsy specimens and surgical specimens for the detection of EGFR mutations and EML4-ALK in non-small-cell lung cancer. Oncotarget. 2016;7(37):59049-59057.

4. Kara M, Alver G, Sak SD, Kavukcu S. Implantation metastasis caused by fine needle aspiration biopsy following curative resection of stage IB non-small cell lung cancer. Eur J Cardiothorac Surg. 2001;20(4):868-870.

5. Scotti V, Di Cataldo V, Falchini M, et al. Isolated chest wall implantation of non-small cell lung cancer after fine-needle aspiration: a case report and review of the literature. Tumori. 2012;98(5):126e-129e.

6. Voravud N, Shin DM, Dekmezian RH, Dimery I, Lee JS, Hong WK. Implantation metastasis of carcinoma after percutaneous fine-needle aspiration biopsy. Chest. 1992;102(1):313-315.

7. Raftopoulos Y, Furey WW, Kacey DJ, Podbielski FJ. Tumor implantation after computed tomography-guided biopsy of lung cancer. $J$ Thorac Cardiovasc Surg. 2000;119(6):1288-1289.

8. Yoshikawa T, Yoshida J, Nishimura M, Yokose T, Nishiwaki Y, Nagai $\mathrm{K}$. Lung cancer implantation in the chest wall following percutaneous fine needle aspiration biopsy. Jpn J Clin Oncol. 2000;30(10):450-452.

9. Shyamala K, Girish HC, Murgod S. Risk of tumor cell seeding through biopsy and aspiration cytology. J Int Soc Prev Community Dent. 2014;4(1):5-11.

10. Louha M, Nicolet J, Zylberberg H, et al. Liver resection and needle liver biopsy cause hematogenous dissemination of liver cells. Hepatology. 1999;29(3):879-882.

11. Hu XC, Chow LW. Fine needle aspiration may shed breast cells into peripheral blood as determined by RT-PCR. Oncology. 2000;59(3) $217-222$.

12. Matsuguma H, Nakahara R, Kondo T, Kamiyama Y, Mori K, Yokoi K. Risk of pleural recurrence after needle biopsy in patients with resected early stage lung cancer. Ann Thorac Surg. 2005;80(6):2026-2031.

13. Inoue $\mathrm{M}, \mathrm{Honda} \mathrm{O}$, Tomiyama $\mathrm{N}$, et al. Risk of pleural recurrence after computed tomographic-guided percutaneous needle biopsy in stage I lung cancer patients. Ann Thorac Surg. 2011;91(4):1066-1071.

14. Flechsig P, Kunz J, Heussel CP, et al. Invasive lung cancer staging: influence of CT-guided core needle biopsy on onset of pleural carcinomatosis. Clin Imaging. 2015;39(1):56-61.

15. Kashiwabara K, Semba H, Fujii S, Tsumura S. Preoperative percutaneous transthoracic needle biopsy increased the risk of pleural recurrence in pathological stage I lung cancer patients with sub-pleural pure solid nodules. Cancer Invest. 2016;34(8):373-377.

16. Asakura K, Izumi Y, Yamauchi Y, et al. Incidence of pleural recurrence after computed tomography-guided needle biopsy in stage I lung cancer. PLoS One. 2012;7(8):e42043. 
17. An J, Yang HP, Hu CP, et al. Multinodule abnormalities of the tracheobronchus: bronchoscopy findings and clinical diagnosis. Clin Respir J. 2017;11(4):440-447.

18. Luo FY, Liu ZH, Hu QH, et al. Association of BTBD7 with metastasis and poor prognosis in non-small-cell lung cancer patients. $J$ Cancer. 2015;6(5):477-481.

19. Chansky K, Sculier JP, Crowley JJ, Giroux D, Van Meerbeeck J, Goldstraw P; International Staging Committee and Participating Institutions. The International Association for the Study of Lung Cancer Staging Project: prognostic factors and pathologic TNM stage in surgically managed non-small cell lung cancer. J Thorac Oncol. 2009;4(7):792-801.

20. Wu F, Liu X, Ma JA, Gao Y, Hu C. Adjuvant therapy for resected EGFRmutant non-small-cell lung cancer. Lancet Oncol. 2018;19(3):e124.

21. Burdett S, Pignon JP, Tierney J, et al; Non-Small Cell Lung Cancer Collaborative Group. Adjuvant chemotherapy for resected early-stage nonsmall cell lung cancer. Cochrane Database Syst Rev. 2015;3:CD011430.

22. Morgensztern D, Du L, Waqar SN, et al. Adjuvant chemotherapy for patients with T2N0M0 NSCLC. JThorac Oncol. 2016;11(10):1729-1735.

23. Steeg PS. Tumor metastasis: mechanistic insights and clinical challenges. Nat Med. 2006;12(8):895-904.
24. Ngamruengphong $\mathrm{S}, \mathrm{Xu} \mathrm{C}$, Woodward TA, et al. Risk of gastric or peritoneal recurrence, and long-term outcomes, following pancreatic cancer resection with preoperative endosonographically guided fine needle aspiration. Endoscopy. 2013;45(8):619-626.

25. Ngamruengphong S, Swanson KM, Shah ND, Wallace MB. Preoperative endoscopic ultrasound-guided fine needle aspiration does not impair survival of patients with resected pancreatic cancer. Gut. 2015;64(7):1105-1110.

26. Loughran CF, Keeling CR. Seeding of tumour cells following breast biopsy: a literature review. Br J Radiol. 2011;84(1006):869-874.

27. Sano Y, Date H, Toyooka S, et al. Percutaneous computed tomographyguided lung biopsy and pleural dissemination: an assessment by intraoperative pleural lavage cytology. Cancer. 2009;115(23):5526-5533.

28. Wisnivesky JP, Henschke CI, Yankelevitz DF. Diagnostic percutaneous transthoracic needle biopsy does not affect survival in stage I lung cancer. Am J Respir Crit Care Med. 2006;174(6):684-688.

29. Wang T, Luo L, Zhou Q. Risk of pleural recurrence in early stage lung cancer patients after percutaneous transthoracic needle biopsy: a metaanalysis. Sci Rep. 2017;7:42762.
Cancer Management and Research

\section{Publish your work in this journal}

Cancer Management and Research is an international, peer-reviewed open access journal focusing on cancer research and the optimal use of preventative and integrated treatment interventions to achieve improved outcomes, enhanced survival and quality of life for the cancer patient. The manuscript management system is completely online and includes
Dovepress

a very quick and fair peer-review system, which is all easy to use. Visit http://www.dovepress.com/testimonials.php to read real quotes from published authors. 